\title{
NEF+ Report
}

\section{Initial Literature Review on Outdoor Learning and Vocational Education and Training}

Grant Agreement Number: 2020-1-PL01-KA226-VET-095905

\begin{tabular}{|l|l|}
\hline Produced by: & Jule Hildmann (PhD), The University of Edinburgh, UK \\
\hline Date: & October 15, 2021 \\
\hline Version: & 2 \\
\hline $\begin{array}{l}\text { Related tasks } \\
\text { (according to NEF+ }\end{array}$ & $\begin{array}{l}\text { Summary of existing research on OL for VET ready for } \\
\text { dissemination (UoE, month 3) (p.75) } \\
\text { UoE will provide international state-of-the-art knowledge on } \\
\text { OL for VET to (a) the Consortium and (b) wider network } \\
\text { members.(p.79) }\end{array}$ \\
\hline Status: & Final version \\
\hline Dissemination level: & public \\
\hline
\end{tabular}

\section{Introduction}

Outdoor, adventure and experiential education (OAE) is widely used and acknowledged as effective pathway to promote personal and social skills and competencies that are relevant in professional life contexts (Burke \& Collins, 2004a). Many outdoor education providers offer specific programmes for apprentices, work groups, and managers, with costumer companies returning year after year with high satisfaction, rendering this "a multi-million pound international industry" (Jones \& Oswick, 2007, 327).

The ERASMUS+ project 'NEF+' aims to promote outdoor learning (OL) for vocational education and training (VET) across Europe. It builds on the successes of the EEA \& Norway Grant funded knowledge transfer project 'From Outdoors to Labour Market / FOLM' which employs the 'Edinburgh Model' of OL (Hildmann et al., in review) to promote transformational competencies and employability skills in young adults in Pola nd, Ireland, and Spain. 


\section{Objectives and context within the NEF+ project}

In line with the project proposal and funding agreement, this report aims to provide a summary of existing research (NEF+ proposal, 75) and international state-of-the-art knowledge on OL for VET (ibid., 79). The report and insights gained from its discussion within the NEF+ Consortium will form the basis for the composition of an evidence-based set of indicators and criteria for a scoping exercise to identify 'Good Practices in OL for VET', and a self-evaluation tool for practitioners and organisations active and/or interested in OL for VET (ibid., 75, 79).

This report is disseminated as the Initial Literature Review within the NEF+ Consortium, and made available to the NEF+ network members and the public (ibid. 79). We refer to it as 'initial' review as we expect to expand our awareness of further aspects and sources around OL for VET in the course of the project. The intention is therefore to revise and potentially expand this report at the end of the NEF+ project.

\section{Structure and Methodology}

The process of this literature review transpired to be more complicated than expected. The following sections describe the phases and details of the search.

\subsection{Academic journals in the field of Outdoor, Adventure and Experiential Education (OAE)}

To formally capture the 'state-of-the-art knowledge on OL for $\mathrm{VET}^{\prime}$ ', a semi-systematic literature review was conducted in three of the main international academic peer-reviewed journals in OAE. While there are differences between the educational approaches of outdoor versus adventure versus experiential education, they are combined here for the merit of their overlaps. Especially in the reviewed journals, outdoor, adventure, and experiential topics are covered that could equally be relevant to this research.

In a first step, repositories of the Journal of Experiential Education (JEE, ISSN 10538259), Journal of Adventure Education and Outdoor Learning (JAEOL, ISSN 14729679), and Journal of Outdoor Recreation, Education and Leadership (JOREL, ISSN 19485123) were consulted through The University of Edinburgh's library search function to identify articles with any of these search terms in the title:

- Labour market

- Employment

- Employability

- Vocational

As this yielded near to no results, and none of relevance, further search terms were applied:

- Work

- Skills

- Transversal

- Transformative

- Competence/-y/-es/-ies

- Training

Across the three journals, no more than 126 papers were identified through this search (see Table 1 ).

\section{THE UNIVERSITY of EDINBURGH}

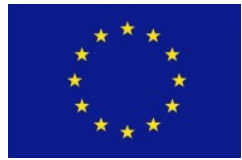




\begin{tabular}{|c|c|c|c|c|c|c|c|c|c|}
\hline \multirow{2}{*}{$\begin{array}{l}\text { Journals: } \\
\\
\text { Search terms for } \\
\text { TITLE }\end{array}$} & \multicolumn{3}{|c|}{$\begin{array}{c}\text { Journal of Experiential } \\
\text { Education }\end{array}$} & \multicolumn{3}{|c|}{$\begin{array}{c}\text { Journal of Adventure } \\
\text { Education and Outdoor } \\
\text { Learning }\end{array}$} & \multicolumn{3}{|c|}{$\begin{array}{l}\text { Journal of Outdoor } \\
\text { Recreation, Education } \\
\text { and Leadership }\end{array}$} \\
\hline & 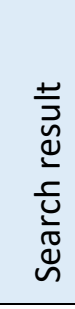 & 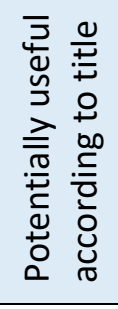 & 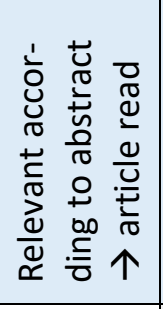 & 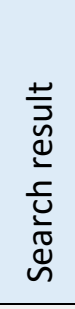 & 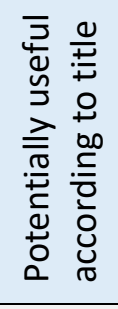 & 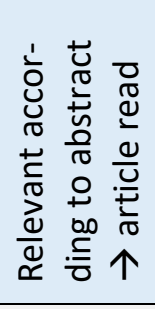 & 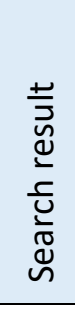 & 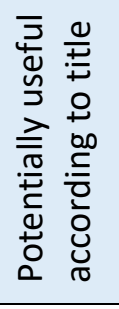 & 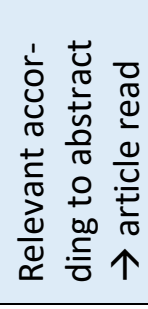 \\
\hline labour market & 0 & 0 & 0 & 0 & 0 & 0 & 0 & 0 & 0 \\
\hline employability & 0 & 0 & 0 & 0 & 0 & 0 & 0 & 0 & 0 \\
\hline employment & 2 & 0 & 0 & 0 & 0 & 0 & 1 & 0 & 0 \\
\hline Vocational & 1 & 0 & 0 & 0 & 0 & 0 & 0 & 0 & 0 \\
\hline transversal & 0 & 0 & 0 & 0 & 0 & 0 & 0 & 0 & 0 \\
\hline transformative & 3 & 2 & 0 & 2 & 2 & 2 & 1 & 1 & 1 \\
\hline work & 18 & 0 & 0 & 4 & 1 & 1 & 1 & 1 & 1 \\
\hline $\begin{array}{l}\text { competence/-y/- } \\
\text { es/-ies }\end{array}$ & 9 & 3 & 1 & 8 & 2 & 2 & 2 & 2 & 1 \\
\hline skills & 20 & 1 & 0 & 9 & 6 & 2 & 7 & 4 & 4 \\
\hline training & 32 & 5 & 2 & 6 & 1 & 1 & 5 & 3 & 0 \\
\hline \multicolumn{3}{|c|}{$\begin{array}{l}\text { Minus papers under several } \\
\text { search terms }\end{array}$} & -1 & & -2 & -2 & & -1 & -1 \\
\hline Overall: & 83 & 11 & 2 & 27 & 10 & 6 & 16 & 10 & 6 \\
\hline
\end{tabular}

Table 1. Results in OAE journals, with varying search terms for article titles

In a second step, the abstracts of these 126 publications were read and rated on a scale of 0-3 on their relevance for this review (see Table 2). Publications with potentially relevant content (rating 1 to 3 ) were obtained and read. The rating was consequently updated where necessary, and relevant content from the publications extracted for the report.

\begin{tabular}{|l|c|c|}
\hline \multicolumn{1}{|c|}{ Rating of identified sources } & $\begin{array}{c}\text { Scale of } \\
\text { relevance (0-3) }\end{array}$ & $\begin{array}{c}\text { No of papers } \\
\text { (incl. overlaps) }\end{array}$ \\
\hline $\begin{array}{l}\text { No connection to the topic/s at all --> not used as source in the } \\
\text { lit review }\end{array}$ & 0 & 12 \\
\hline $\begin{array}{l}\text { Some connection to TCs, yet not of sufficient depth or } \\
\text { relevance to be of use. l.e. source not used in the current } \\
\text { report. }\end{array}$ & $2 a$ & 9 \\
\hline $\begin{array}{l}\text { Some relevance to Transformative/Transversal/Transferable } \\
\text { Competencies (with or without explicitly using these terms, } \\
\text { TCs) }\end{array}$ & $2 b$ & 4 \\
\hline Some relevance to VET & $3 a$ & 2 \\
\hline Key relevance for OL/OEL and TCs & $3 b$ & 2 \\
\hline Key relevance for OL/OEL and VET & & 31 \\
\hline \multicolumn{1}{|c|}{ Total number of papers rated } & 3b \\
\hline
\end{tabular}

Table 2. Rating of identified papers in outdoor learning related academic journals 
In terms of content, this entire search yielded very few relevant insights, despite widening the search terms. Two noteworthy concepts that came up are Outdoor Management Development (OMD) and Corporate Adventure Training (CAT). They will be discussed below. Apart from these, seemingly no article in the OAE literature directly addresses $\mathrm{OL}$ as approach to promote vocational and/or labourmarket skills - whether theoretically or with research evidence. Where professional skills and training are the topic of the publication, these are nearly all focussed on professions in the outdoors, primarily OAE. Such OAE-specific literature was not further pursued for this report because the pivot point of using OL for VET is that social emotional skills developed through outdoor learning programmes transfer into the home (e.g., work) context. For professionals training for an OAE profession however, the learning and application setting are the same (i.e. outdoors, and outdoor activities) and therefore the objectives blurred and the key point of transference not given to the extent relevant to OL for VET.

Equally, a plethora of sources discusses outdoor professionals from the perspective of leadership theories. And while there is an overlap of the skills, competencies and leadership elements relevant to OAE professions with those on the general labour market, the specific focus on this professional context does not support a generalisation to all professions and the general labour market.

\subsection{Vocational and workplace-related journals}

The lack of papers found in the OAE journals led to the hypothesis that research and knowledge on OL for VET is disseminated in other academic journals - presumably in vocational and work-related journals. Therefore, a second literature review was attempted, with the search term 'outdoor' in the titles of articles in 13 international academic journals containing 'Vocational', 'Employment', Labour market' or 'Occupational' in the journal title (see Table 3).

\begin{tabular}{|l|c|c|c|}
\hline \multicolumn{1}{|c|}{ Journal } & ISSN & $\begin{array}{c}\text { Articles } \\
\text { found }\end{array}$ & $\begin{array}{c}\text { Scale (0- } \\
\text { 3) }\end{array}$ \\
\hline Journal of Vocational Education \& Training & $\begin{array}{c}1363-6820, \\
1747-5090\end{array}$ & 0 & 0 \\
\hline International Journal of Vocational Education and Training & 10752455 & 0 & 0 \\
\hline Vocational Education Journal & 08848009 & 1 & 0 \\
\hline The Journal of Vocational Education Research & $\begin{array}{c}15547574, \\
07393369\end{array}$ & 0 & 0 \\
\hline Vocational Aspect of Education & 03057879 & 0 & 0 \\
\hline Journal of Vocational Behavior & $\begin{array}{c}10959084, \\
00018791\end{array}$ & 0 & 0 \\
\hline International Journal of Employment Studies & 10396993 & 0 & 0 \\
\hline OECD Employment Outlook & $\begin{array}{c}19991266, \\
10130241\end{array}$ & 0 & 0 \\
\hline International Employment Relations Review & 13241125 & 0 & 0 \\
\hline Economic \& Labour Market Review & $\begin{array}{c}17518326, \\
17518334\end{array}$ & 0 & 0 \\
\hline Journal of Labour Market Research & $\begin{array}{c}25105027, \\
25105019\end{array}$ & 1 & 0 \\
\hline OECD Labour Market and Social Policy Occasional Papers & 18151981 & 0 & 0 \\
\hline
\end{tabular}


Journal of Occupational Science

21581576,

14427591

1

Table 3. Results in vocational and work-related journals, with outdoor as search term for articles

Only three brought up any results at all, none of which was relevant to this review.

\subsection{General search with academic search engines}

To make a final and more general attempt to identify suitable literature and research on OL for VET, the academic search engine Pro Quest was fed with the search terms Outdoor plus each of the three key terms Employment, Vocation/al, and Labour market (see Table 4).

\begin{tabular}{|c|c|c|c|}
\hline \multirow{2}{*}{ Search term Outdoor plus } & \multicolumn{3}{|c|}{ Articles found } \\
\cline { 2 - 4 } & ERIC & Pro Quest & EBSCOhost \\
\hline Vocational & $3(0)$ & $5(0)$ & $1(1)$ \\
\hline Employment & $7(0)$ & $\begin{array}{c}>16.000 \\
(0 \text { in the first 50) } \\
>11.000 \\
(0 \text { in the first 50) }\end{array}$ & $4(0)$ \\
\hline Labour market & 0 & 0 \\
\hline
\end{tabular}

Table 4. Search results with different academic search engines

With ProQuest, the search produced several thousand hits, the first 50 were checked. If these contained zero relevant papers, then the rest were discarded as well. Also, fewest of the ones checked actually related to outdoor topics.

At this point, several options to progress were open:

- To further widen the search terms (e.g., leadership; social emotional learning / SEL; nature). This however would have produced a flood of results that while potentially containing relevant content would have left the focus of OL and/or VET.

- To close the formal search activity and set the few identified papers in connection to general $\mathrm{OL}$ and other literature.

The second approach seemed a lot more conducive to the purpose of this report, and the following findings are presented and discussed in this way.

\section{Findings and Discussion}

\subsection{Outdoor Management Development (OMD) and Corporate Adventure Training (CAT)}

The terms Outdoor Management Development (OMD) and Corporate Adventure Trainings (CAT) refer to (mostly short-term) training events for business staff and managers that usually comprise a series of problem-solving tasks combined with reflection exercises and theoretical inputs in order to further the participants' team performance and managerial or leadership skills Kourtesopoulou and Kriemadis (2020). Common course objectives include working on and improving the participants' strengths and 
weaknesses, personal limits and skills, team work, social cohesion through shared positive experiences and fun, intrapersonal and interpersonal barriers, and trust building (Kourtesopoulou and Kriemadis, 2020; Priest; 1998).

Different studies on OMD courses reported increases in participants'

- Awareness of self

- Accountability

- Team interaction

- Sense of satisfaction

- Effective communication

- Performance around decision-making

- Use of member talents

- Team morale

- Satisfaction with relationships with authority figures

- Overall work and team performance

(Combined from O'Bannon, 2000; Rodenbaugh, 2002; Kourtesopoulou \& Kriemadis, 2020).

Jones \& Oswick (2007) lament that despite OMD and CAT having such a big economy and market, there is little research, particularly into the mechanisms by which outcomes are achieved.

Burke \& Collins (2004a) propose a framework for OMD that helps investigate and enhance the development of the selected focus of conflict management skills in managers. They see the relevance of the outdoor learning setting in that "the outdoor phase and subsequent reviews [is] expected to provide opportunities for clients to practice and adapt their skills" (ibid., 681). Presenting a practice ground and conducive factors for learning is the general purpose of OL settings. The authors (2004a; b) emphasize the importance of transfer of learning from the training to the 'real', i.e. work context, and argue that "despite a rapid expansion of [OMD] provision, there remains a dearth of both empirical evidence and theoretical perspectives to support theories related to the efficacy of the learning process and, crucially, its transfer to the work place" (Burke \& Collins, 2004a, 715). The issue of transfer is links to the key question of effectiveness and legitimacy of OAE in general - independent of the VET context - and a lot of research and literature is concerned with exploring and improving it (e.g., Leberman \& Martin, 2004; Sipthorp et al., 2011). It seems safe to assume that for OL for VET this general literature can be gleaned on for guidance.

Furthermore, Kourtesopoulou and Kriemadis (2020) also report increased evidence for transformational leadership style (cf. Avolio \& Bass, 2004) and teamwork. Developing leadership skills and styles is a very common objective of OAE programmes, not just for managers yet a range of populations. Consequently, a wealth of literature is available on OAE and leadership (e.g., Anderson, Zwart, \& Ewert, 2020; Martin, Breunig, Wagstaff, \& Goldenberg, 2017; Hayashi \& Ewert, 2006). Since the conceptualisation of and research around leadership in OAE goes way beyond corporate leadership - let alone VET - this body of literature is not pursued further in this review.

\subsection{VET-related learning outcomes}

The few publications the search produced beyond the OMD and CAT articles are consistent with findings on outcomes and factors of impact in the general OL literature and not even all specifically directed at VET. Here are a few examples:

Rhodes and Martin $(2013 ; 2015)$ examined what factors led to positive changes in workplace attitude and behaviour. Their study participants were soldiers in the New Zealand Army, and some of the 
learning outcomes they observed are somewhat specific to a military leadership setting (e.g., control behavior, decision making, and communication under stress; understanding the importance of, and managing, reputation rather than identity), while others are relevant in a range of contexts, such as:

- To build trust and relationships

- Understanding and making choices about personal behaviour

- Considering the impacts of behaviours on others.

The authors found positive changes in the self-report data of participants in all of the examined (i.e. desired) course outcomes.

With a similarly specific target group, McCleary and Chesteen (1990) investigated the impact of a shared OAE course for physically disabled and able-bodied participants on their attitude towards employment, self efficacy and perceived barriers caused by stereotypes around disabilities. Their pre and post self-report questionnaires on self-esteem, personal efficacy and social behaviour revealed increases - albeit not statistically significant - in the participants with disabilities' confidence to seek employment, positive self-concept and sense of efficacy.

Many OAE programmes can be found that are designed for persons in the criminal justice system with the aim to support their (re)integration into society and a healthy, regulated lifestyle including housing and employment. Fletcher (2001) investigates such programmes and argues that the exciting outdoor/adventure activities increase participants' motivation (881), and that "most importantly, outdoor activities can provide an opportunity for individuals to experience success, [which] is vital in building self-esteem and confidence" (ibid., 882) which in turn raises their commitment and chance of success (ibid.). The same mechanism applies in courses for people recovering from addiction, or (mental) health crises, or army veterans who often experience a combination of issues (e.g., addiction, physical and mental health problems, relationship breakdowns, unemployment). Improving participants' self-esteem and sense of agency empowers them to take more self-directed actions around relationships, self-management and life choices - including VET (e.g., GAP 2018; Fletcher 2001).

Anderson, Zwart and Ewert (2020) compared the development and post-course application of transferable skills in participants of outdoor versus 'non-outdoor' leadership programmes. Using a mixed-method design, they found that the investigated OL programmes - especially the one of several weeks length - produced the highest increase in what the authors call 'transferable skills':

- Leadership

- Teamwork

- Decision-making

- Reflexivity

- Confidence (Anderson et al., 2020, 127f.).

Stott and Hall (2007) report significant changes in self-report data of 60 young (i.e age 16-20) expeditioners to Arctic Greenland in a range of personal, social and technical skills. Ignoring skills that are specific to Arctic conditions (e.g. avoid depression; cope with constant cold; enjoy isolation), several general ones include the abilities to

- Set priorities

- Achieve goals

- Solve problems efficiently

- Manage time efficiently

- Maintain physical fitness 
- Be enthusiastic

- Demonstrate confidence

- Set goals

- Control their emotions

- Motivate others

(ibid., 164). The researchers argue that "the personal and social skills and traits examined may be readily transferable to higher education or employment" (ibid., 167).

And as a final example, Sipthorp (2003) interviewed adolescents in sailing and diving programmes and found increases in transferable 'life skills', such as

- personal awareness

- leadership

- tolerance of others

- patience.

Sipthorp argues that these outcomes have the "potential to transfer to school, work, and optimal functioning at home" (ibid., 155).

More studies are available with similar findings. While all the reported learning outcomes are certainly of use in VET contexts, they are not restricted to it and equally valuable in other life contexts. In fact, we have not found near to no publication on OL in connection with genuine VET settings, courses, groups or VET-curriculum-related learning objectives. However, the cited papers refer explicitly or implicitly to transferrable competencies or life skills, implying a wide applicability of learning from OL courses, including VET and employability. The skills, traits and attitudes listed here are in line with the competencies called for in VET, as will be shown in the following section.

\subsection{International frameworks for educational objectives}

With the diverse terminology used around personal, self-, socio-emotional, social, etc. skills and competencies, and sheer countless items of traits, attitudes, behaviours and what not subsumed under any of these - depending on authors -, a framework is needed to structure the evidence sufficiently for a clear understanding which skills/competencies are desired for VET, and to what degree OL/OAE programmes can promote these.

Fortunately, such frameworks already exist. Both the OECD $(2005 ; 2019)$ and the UNESCO $(2015)$ have conducted extensive research and compiled lists of transferable competencies that are internationally agreed to be crucial for success and contentment in personal and professional contexts. While these lists and terminology are not identical, there are substantial similarities. A comparison with findings of some of the meta-analyses that are regarded as cornerstones of OAE literature demonstrates significant overlaps of the skills and competencies called for internationally, and common learning outcomes of OL/OAE programmes - including the VET-related ones cited above:

- Teamwork, cooperation

- Problem-solving, flexibility and creative thinking

- Conflict resolution, dealing with dilemmas

- Critical thinking and reflection

- Taking responsibility (for self, actions, others, the planet)

- Respect, tolerance, openness 
(See also Ewert \& Sipthorp, 2014, 126-135; Neill/Richards 1998, 2; Kourtesopoulou \& Kriemadis, 2020). In addition to these, research has frequently shown OL/OAE to also promote underlying elements such as sense of agency, self-efficacy and locus of control (Hans, 2000), and physical and mental health and wellbeing (Ewert \& Sipthorp, 2014).

\subsection{Factors of impact identified in VET-related studies}

Not all studies that investigate the impact of $\mathrm{OL}$ also address or identify the internal or external factors that contribute to the learning outcomes. In the wider OAE literature, quite a number of studies are available by now, in respect to VET merely very few. Among these, Rhodes and Martin (2015) used questionnaire data and identified as key factors in the OL programme that led to the desired learning outcomes:

- Being challenged

- Seeing the relevance of the objectives and learning in the course for their work environment

- Post-course mechanisms and strategies to activate and apply course learning

- Post-course reflection

Sipthorp's (2003) study adds as factors that contributed to participants' learning:

- Practical, multi-sensory interaction with the learning subject, material and tools

- Social learning through modelling and interaction with peers

- Necessity of learning due to authentic constraints of OAE/OL settings

And Anderson et al. (2020) add:

- Length of the programme

All of these factors are in line with the general OAE/OL literature and research:

Being challenged has frequently been identified as a key factor to promote personal and social competence in OL programmes with some discussion and research around the optimal ways and context of challenge in order to achieve positive results (e.g. David-Berman \& Berman, 2002; Leberman \& Martin, 2003; McKenzie, 2000; 2003; Rhodes \& Martin, 2015).

Seeing the relevance of learning objectives for future applications (such as work life) is part of Dewey's (1938) condition of Continuity, i.e. the educational experience building on potential previous experiences and insights, and - more importantly - gaining meaning and relevance through a trajectory towards a future, real-life application. Dewey's philosophy is often seen as one of the foundations for outdoor and experiential education, and the real-life context and application is also frequently highlighted in the literature (e.g., Sipthorp, 2003).

Post-course mechanisms and strategies to activate and implement course learning can form a valuable contribution to support transfer of learning from the OL course to the 'home' (i.e. work, school, etc.) context and environment of the participants. Whether or not support and facilitated strategies for such transfer are in place has long been identified in $\mathrm{OL}$ literature as a responsible factor for the longevity or fading out of skills and insights gained from a course (e.g., Sipthorp, Furman, Paisley, Gookin, \& Schumann, 2011). The learning effects can be maintained and even enhanced through practical means such as an action plan "to help [participants] remember to apply what [they have] learned" (Rhodes \& Martin, 2015, 116) or individual and group-based post-course reflection exercises (Leberman \& Martin, 2004; Rhodes \& Martin, 2015). 
Reflection is indeed a factor identified critical for learning in general (Hattie, 2008), independent of OL and/or VET. Nevertheless, debriefing, reviewing and reflection - terminology depending on the source, yet with near identical meaning - is a central part of outdoor and experiential education, with several models on how, when, and to what purpose to review are content of any professional training in outdoor/adventure/experiential education (Asfeldt, Hvenegaard, \& Purc-Stephenson, 2018; Coulson \& Harvey, 2013; Leberman \& Martin, 2004). Neuropsychological research confirms that the verbal or nonverbal, individual or communal reviewing of an experience makes is accessible to cognitive processing and learning derived from it more easily transferable and applicable. It is the 'head' in the famous mantra of experiential learning of 'with head, heart and hand').

Necessity of learning due to authentic constraints of OAE settings. The constraints, adversity and unpredictability of outdoor settings are central in creating the real-life requirements and thereby the meaningful, authentic challenges discussed above that lead to skill development (Anderson et al. (2020; Priest, 1998; Sipthorp, 2003).

Programme length. Several studies confirm that longer and over night OL programmes generally produce stronger results than shorter ones (Fiennes et al. 2015; Hattie et al. 1997, 62f.; Rickinson et al. 2004; Sipthorp, 2003; Todd et al. 2007; 2008). Longer programmes afford more opportunities to practice new skills and attitudes, and a higher chance for significant experiences to occur, which can help reactivate and transfer learning. The research and academic discussion around transfer of learning confirms this (Burke \& Hutchins, 2007).

\section{Conclusions}

It is astonishing to find such a divide between OL for VET being a well-established practice by many outdoor education providers in Europe and beyond, while the literature evidence and research focussing specifically on OL for VET is so minimal. However, the OAE literature contains an abundance of studies with school-aged youth, adolescents, college students, and adults with different demographic criteria. The reported findings of the little available VET-related literature are completely in line with general OAE literature, and the reported learning outcomes both in VET as well as other OL programmes match well with the transferable skills and competencies called for in international educational frameworks. Therefore, it can be convincingly deduced that $\mathrm{OL}$ is a suitable and effective approach to develop and train employability- and workplace-related skills and competencies - in fact, according to comparative research, more so than traditional indoor courses (Anderson et al., 2020; Priest, 1998). Practice confirms this with a thriving market of outdoor-based work-skill-oriented training programmes for managers, apprentices and work groups (Burke \& Collins, 2004a; Jones \& Oswick, 2007).

Nevertheless, it is surprising that there is minimal literature on OL specifically for the purpose of VET. Potentially, the general reading is that the skills and competencies that are common learning outcomes of OL/OAE programmes are transferable to a range of contexts, which often explicitly includes the workplace, and that therefore no specific texts on this are required. Nevertheless, this seems to be a gap.

Within the NEF+ project, the available literature and frameworks provide sufficient guidance for the composition of the planned list of indicators and criteria to scope for 'Good Practices' in OL for VET. 
Where feasible and within the UoE staff's capacity, we might combine the international scoping exercise with some research activities to provide data and insights to further the field's knowledge and fill this identified gap.

For practice and policy it is evident that OL for VET is widely established, as OMD/CAT courses for managers, as team development events, and as development programs for youth and young adults. The NEF+ project with its scoping exercise has the potential to explore, contrast and disseminate the diversity and value of this approach for VET and other life contexts.

\section{Sources}

Anderson, K.R., Zwart, R., \& Ewert, A. (2020). A Comparison of Transferable Skill Development in Both Experiential Leadership Curriculums and Traditional Leadership Curriculums. Journal of Outdoor Recreation, Education, and Leadership 12(2), 217-221. https://doi.org/10.18666/JOREL-2020-V12-12-9873

Asfeldt, M., Hvenegaard, G., \& Purc-Stephenson, R. (2018). Group Writing, Reflection, and Discovery: A Model for Enhancing Learning on Wilderness Educational Expeditions. Journal of Experiential Education, 41(3), 241-260. doi:10.1177/1053825917736330

Avolio, B. J., \& Bass, B. M. (2004). Multifactor Leadership Questionnaire ${ }^{\text {TM }}$. Third Edition. Manual and SampleSet. Mind Garden, Inc.

Burke, L. A., \& Hutchins, H. M. (2007). Training transfer: An integrative literature review. Human Resource Development Review, 6(3), 263-296.

Burke, V., \& Collins, D. (2004a). Optimising skills transfer via outdoor management development: Part I: The provider's perspective. The Journal of Management Development, 23(7), 678-696. doi:http://dx.doi.org.ezproxy.is.ed.ac.uk/10.1108/02621710410546678

Burke, V., \& Collins, D. (2004b). Optimising skills transfer via outdoor management development: Part II: The client's perspective. The Journal of Management Development, 23(7), 715-728. doi:http://dx.doi.org.ezproxy.is.ed.ac.uk/10.1108/02621710410549576

Coulson, D., \& Harvey, M. (2013). Scaffolding student reflection for experience-based learning: A framework. Teaching in Higher Education, 18(4), 401-413.

Davis-Berman, J., \& Berman, D. (2002): Risk and Anxiety in Adventure Programming. The Journal of Experiential Education, 25(2), 305-310.

Dewey, J. (1938) Experience and education. New York: Collier Books.

Ewert, A. W., \& Sibthorp, J. (2014). Outdoor Adventure Education. Foundations, Theory, and Research. Champaign, IL: Human Kinetics.

Fiennes, C., Oliver, E., Dickson, K., Escobar, D., Romans, A., \& Oliver, S. (2015). The Existing EvidenceBase about the Effectiveness of Outdoor Learning. Final Report - Executive Summary. Institute for Outdoor Learning (IOL) \& Blagrave Trust (Eds.).

Fletcher, D.R. (2001). Ex-offenders, the labour market and the new public administration. Public Administration, 79(4), 871-891.

GAP Communications (2018). Evaluation of the Positive Futures Programme 2016-2018. For veterans struggling with civilian life. URL: https://50ca3b8f-d6ee-4332-91cf- 
0330d1510970.filesusr.com/ugd/9df89b_eb558abca15f4c869337e40e3a59ec30.pdf

Hamilton, T. A., \& Cooper, C. (2001). The impact of outdoor management development (OMD) programmes. Leadership \& Organization Development Journal, 22(7), 330-340. doi:http://dx.doi.org.ezproxy.is.ed.ac.uk/10.1108/EUM0000000006163

Hans, T. A. (2000). A meta-analysis of the effects of adventure programming on locus of control. Journal of Contemporary Psychotherapy, 30(1), 33-60.

Hattie, J. (2008). Visible Learning. A Synthesis of Over 800 Meta-Analyses Relating to Achievement. Abingdon: Routledge.

Hattie, J., Marsh, H.W., Neill, J.T., \& Richards, G.E. (1997). Adventure Education and Outward Bound: Out-of-Class Experience that make a lasting difference. Review of Educational Research, 67(1), 43-87. DOI: https://doi.org/10.3102/00346543067001043

Hayashi, A., \& Ewert, A. (2006). Outdoor Leaders' Emotional Intelligence and Transformational Leadership. Journal of Experiential Education, 28(3), 222-242).

Hildmann, J., Higgins, P., White, S., Strang, M., \& Hardie, A. (in review). Empowerment towards social and personal competence through wilderness journeys - the Edinburgh Model. Submitted to the Journal of Transformative Education.

Jones, P.J. and Oswick, C. (2007), Inputs and Outcomes of Outdoor Management Development: Of Design, Dogma and Dissonance. British Journal of Management, 18: 327-341. https://doiorg.ezproxy.is.ed.ac.uk/10.1111/j.1467-8551.2006.00515.x

Kourtesopoulou, A., \& Kriemadis, A. (2020): Exploring the influence of Outdoor Management Development (OMD) program on leadership and teamwork competencies, Journal of Adventure Education and Outdoor Learning, DOI: 10.1080/14729679.2020.1784763

Leberman, S. I., \& Martin, A. J. (2004). Enhancing transfer of learning through post-course reflection. Journal of Adventure Education and Outdoor Learning, 4(2), 173-184. http://dx.doi.org/10.1080/14729670485200521

Leberman, S. I., \& Martin, A. J. (2003). Does pushing comfort zones produce peak learning experiences. Australian Journal of Outdoor Education, 7(1), 10-19.

Martin, B., Breunig, M., Wagstaff, M., \& Goldenberg, M. (2017). Outdoor Leadership. Theory and Practice. Second Edition. Champaign, IL: Human Kinetics.

McCleary, I.D., \& Chesteen, S.A. (1990). Changing attitudes of disabled persons through outdoor adventure programmes. International Journal of Rehabilitation Research, 13, 321-324.

NEF+ Consortium (2020). NEF+ project proposal. Submitted through ECAS to the ERASMUS+ funding Call. Unpublished.

Neill, J.T., \& Richards, G. T. (1998). Does Outdoor Education really work? A summary of recent metaanalyses. Journal of Outdoor and Environmental Education, 3(1), 2-9.

O'Bannon, P. M. (2000). The effects of the outdoor experiential ropes course on perceived team performance. PhD thesis. Florida International University.

OECD / Organisation for Economic Co-operation and Development. (2005). The definition and selection of key competencies: Executive summary. Retrieved from http://www.oecd.org/pisa/35070367.pdf 
OECD. (2019). OECD Future of Education and skills 2030: Thought Leader written statement.

Retrieved from http://www.oecd.org/education/2030-project/teaching-and-

learning/learning/transformative-

competencies/Thought leader written statement Rychen.pdf

Pinkerton, J.B. (1964). The Youth Development and Conservation Corps in the State of Washington. Journal of Forestry, Volume 62, Issue 6, June 1964, Pages 373-375, https://doi.org/10.1093/jof/62.6.373

Priest, S. (1998). Physical challenge and the development of trust through corporate adventure training. The Journal of Experiential Education, 21(1), 31-34. Retrieved from https://wwwproquest-com.ezproxy.is.ed.ac.uk/scholarly-journals/physical-challenge-development-trustthrough/docview/275022217/se-2 ?accountid=10673

Rhodes, H.M., \& Martin, A.J. (2015). Factors Affecting Workplace Outcomes: Examining the New Zealand Army's Experiential Leadership Courses. Journal of Outdoor Recreation, Education, and Leadership 7(2), 112-127.

Rickinson, M. et al. (2004). A Review of research on outdoor learning. National Foundation for Educational Research and King's College London.

Rodenbaugh, M. H. (2002). The effectiveness of experiential education in executive development. PhD thesis, Walden University: U.S.A.

Sipthorp, J., Furman, N., Paisley, K., Gookin, J., \& Schumann, S. (2011). Mechanisms of Learning Transfer in Adventure Education: Qualitative Results from the NOLS Transfer Survey. Journal of Experiential Education, 34(2), 109-126.

Sibthorp, J. (2003) Learning transferable skills through adventure education: The role of an authentic process. Journal of Adventure Education \& Outdoor Learning, 3:2, 145-157, DOI: $10.1080 / 14729670385200331$

Stott, T., \& Hall, N. (2003). Changes in aspects of students' self-reported personal, social and technical skills during a six-week wilderness expedition in Arctic Greenland. Journal of Adventure Education \& Outdoor Learning, 3(2), 159-169. DOI: 10.1080/14729670385200341

Todd, S.L., O'Connell, T., Breunig, M., Young, A., Anderson, L., \& Anderson, D. (2008). The effect of leadership style on sense of community and group cohesion in outdoor pursuit trip groups. Paper presented at the Coalition for Education in the Outdoors Ninth Biennial Research Symposium, Bradford Woods, Indiana University's Outdoor Center, Martinsville.

Todd, S.L., Young, A., O'Connell, T., Anderson, L., Anderson, D., \& Breunig, M. (2007, April). Sense of community and group cohesion in outdoor pursuits trip groups. Paper presented at the Northeast Recreation Research Conference, Bolton Landing, NY.

UNESCO. (2015). Transversal competencies in education policy and practice. Regional synthesis report, Phase I. Retrieved from https://transversalcompetencies.weebly.com/uploads/2/8/4/2/28422343/transversal.pdf

Zins, J.E., Bloodworth, M.R., Weissberg, R.P., \& Walberg, H.J. (2007). The Scientific Base Linking Social and Emotional Learning to School Success. Journal of Education and Psychological Consultation, 17(2-3), 191-210. DOI: 10.1080/10474410701413145 